\title{
Biomass as blast furnace injectant - Considering availability, pretreatment and deployment in the Swedish steel industry ${ }^{\text {is }}$
}

\author{
Chuan Wang a , Pelle Mellin ${ }^{\mathrm{b}, *}$, Jonas Lövgren ${ }^{\mathrm{c}}$, Leif Nilsson ${ }^{\mathrm{c}}$, Weihong Yang ${ }^{\mathrm{b}}$, Hassan Salman ${ }^{\mathrm{d}}$, \\ Anders Hultgren ${ }^{\mathrm{e}}$, Mikael Larsson ${ }^{\mathrm{a}, \mathrm{f}}$ \\ a Swerea MEFOS, Process Integration Department, Box 812, 97125 Luleå, Sweden \\ ${ }^{\mathrm{b}}$ KTH Royal Institute of Technology, Division of Energy and Furnace Technology, Brinellvägen 23, 10044 Stockholm, Sweden \\ ' $S S A B$ Europe, 97188 Luleå, Sweden \\ ${ }^{\mathrm{d}}$ Sveaskog, Kolmilavägen 17, 94137 Piteå, Sweden \\ e SCA Energy, 85188 Sundsvall, Sweden \\ ${ }_{\mathrm{f}}^{\mathrm{f}}$ Energy Engineering, Department of Engineering and Mathematics, Luleå University of Technology, 97187 Luleå, Sweden
}

\section{A R T I C L E I N F O}

Article history:

Available online $\mathrm{xxxx}$

\section{Keywords:}

Biomass

Coal

Blast furnace

Steelmaking

\begin{abstract}
A B S T R A C T
We have investigated and modeled the injection of biomass into blast furnaces (BF), in place of pulverized coal (PC) from fossil sources. This is the easiest way to reduce $\mathrm{CO}_{2}$ emissions, beyond efficiencyimprovements. The considered biomass is either pelletized, torrefied or pyrolyzed. It gives us three cases where we have calculated the maximum replacement ratio for each. It was found that charcoal from pyrolysis can fully replace PC, while torrefied material and pelletized wood can replace $22.8 \%$ and $20.0 \%$ respectively, by weight.

Our energy and mass balance model (MASMOD), with metallurgical sub-models for each zone, further indicates that (1) more Blast Furnace Gas (BFG) will be generated resulting in reduced fuel consumption in an integrated plant, (2) lower need of limestone can be expected, (3) lower amount of generated slag as well, and (4) reduced fuel consumption for heating the hot blast is anticipated. Overall, substantial energy savings are possible, which is one of the main findings in this paper.

Due to the high usage of PC in Sweden, large amounts of biomass is required if full substitution by charcoal is pursued ( $6.19 \mathrm{TWh} / \mathrm{y}$ ). But according to our study, it is likely available in the long term for the blast furnace designated M3 (located in Luleå).

Finally, over a year with almost fully used production capacity (2008 used as reference), a $28.1 \%$ reduction in on-site emissions is possible by using charcoal. Torrefied material and wood pellets can reduce the emissions by $6.4 \%$ and $5.7 \%$ respectively. The complete replacement of PC in BF M3 can reduce $17.3 \%$ of the total emissions from the Swedish steel industry.
\end{abstract}

(c) 2015 Elsevier Ltd. All rights reserved.

\section{Introduction}

The scrap-based steelmaking is often highlighted as the future resource-efficient way of producing steel. The emissions-intensive ore-based route still dominates because of a simple fact, the recycled steel cannot yet supply the volume needed worldwide (only about $30 \%$ as of now [1]). Therefore, more virgin materials are needed in the loop of recycling and thus it is projected, considering the world population growth; that Blast Furnace (BF)

This article is based on a four-page proceedings paper in Energy Procedia Volume 61 (2015). It has been substantially modified and extended, and has been subject to the normal peer review and revision process of the journal.

* Corresponding author.

E-mail addresses: chuan.wang@swerea.se (C. Wang), pmellin@kth.se (P. Mellin). and Direct Reduced Iron (DRI) production will continue to dominate until at least 2050 [1].

Climate change, however, calls for a quicker response. Targets in the European Union (EU) call for a $20 \%$ cut in $\mathrm{CO}_{2}$ emissions, a $20 \%$ improvement in energy efficiency and a $20 \%$ increase of renewable energy, by 2020 . According to EU ambition, an $80 \%$ cut should be achieved until 2050, while the Swedish ambition is to cut $100 \%$ in net $\mathrm{CO}_{2}$ emissions. This paper addresses the seemingly irreconcilable need for steel and cuts in emissions, by presenting research on how to reduce the footprint of blast furnaces. The idea is to replace pulverized coal (an auxiliary fuel), which is injected in large amounts in Swedish blast furnaces. The needed biomass is found in ample amounts in Sweden and available knowledge suggests that operating conditions will not be fundamentally affected [2-6]. 


\section{Nomenclature}

\section{Expressions}

Top gas temperature Outlet temperature at the top of a BF Hot stove Heat exchanger for preheating the blast or hot air Shaft efficiency $\left(\% \mathrm{CO}_{2} /\left(\% \mathrm{CO}_{2}+\% \mathrm{co}\right)\right)_{\mathrm{TRZ}} /\left(\% \mathrm{CO}_{2} /\left(\%_{\mathrm{CO}_{2}}+\% \mathrm{co}\right)\right)_{\text {equilibrium }}$

$\begin{array}{ll}\text { Abbreviations } \\ \text { BF } & \text { Blast Furnace } \\ \text { BFG } & \text { Blast Furnace Gas or Top gas } \\ \text { CFD } & \text { Computational Fluid Dynamics } \\ \text { COG } & \text { Coke Oven Gas } \\ \text { DRI } & \text { Direct Reduced Iron } \\ \text { EU } & \text { European Union } \\ \text { RAFT } & \text { Raceway Adiabatic Flame Temperature }\left({ }^{\circ} \mathrm{C}\right) \\ \text { HM } & \text { Hot Metal or crude iron } \\ \text { tHM } & \text { ton of Hot Metal }(\mathrm{t}) \\ \text { HTC } & \text { Hydrothermal Carbonization } \\ \text { LCA } & \text { Life Cycle Assessment } \\ \text { LHV } & \text { Lower Heating Value }(\mathrm{MJ} / \mathrm{kg}) \\ \text { M2 } & \text { Masugn 2, blast furnace in Oxelösund }\end{array}$

M3 Masugn 3, blast furnace in Luleå

M4 Masugn 4, blast furnace in Oxelösund

PCI Pulverized Coal Injection

SE Steam Explosion

Eta CO Gas utilization efficiency $\% \mathrm{CO}_{2} /\left(\%_{\mathrm{CO}_{2}}+\% \mathrm{cO}\right)_{\text {theoretical }}$ TRZ Thermal Reserve Zone

\section{Roman letters}

$\begin{array}{ll}\mathrm{C} & \text { Carbon content }(\% \mathrm{wt}) \\ \mathrm{H} & \text { Hydrogen content }(\% \mathrm{wt}) \\ \mathrm{h} & \text { hour } \\ \mathrm{N} & \text { Nitrogen content }(\% \mathrm{wt}) \\ \mathrm{O} & \text { Oxygen content }(\% \mathrm{wt}) \\ \mathrm{S} & \text { Sulfur content }(\% \mathrm{wt}) \\ \mathrm{T} & \text { Temperature }(\mathrm{K}) \\ \mathrm{t} & \text { ton }(1000 \mathrm{~kg}) \\ \mathrm{y} & \text { year } \\ \mathrm{W} & \text { Watt }(\mathrm{J} / \mathrm{s})\end{array}$

As such, this study aims to investigate the simplest application of biomass, to give a realistic replacement potential in the near future. Availability of biomass is another concern, which could prohibit the, more challenging, substitution of all fossil fuel in the steel industry. The considered pretreatments (carbonization, torrefaction and pelletization) are used from the outset as scenarios. For each pretreatment, the maximum replacement ratio is calculated, in addition to the effect on operating conditions (see Sections 3.1 and 4.1 for methodology and results respectively), then the needed biomass versus the available biomass is estimated (see Sections 3.2 and 4.2) and finally the corresponding maximum reduction in $\mathrm{CO}_{2}$ emissions are estimated (see Sections 3.3 and 4.3).

This introduction is followed by a background, which covers motive and the previous work in this field. A methodology section describes how this study is carried out and Section 4 describes the results, followed by Section 5 -the conclusions.

\section{Background}

Efforts to reduce $\mathrm{CO}_{2}$ emissions in Sweden have been refocused, from generating renewable power and district heating, to supplying renewable fuels for industry and transportation. The steelmaking sector in Sweden is a large contributor to emissions, which calls for a concentrated effort, but it is by far not the simplest case where renewables may be introduced. The reason is a lock-in effect, which stems from long investments in fossil-based technology, but also energy saving measures. Integrating the steel production (e.g. using Coke Oven Gas (COG) as fuel-supply in other parts of the plant) results in better energy efficiency, but at the same time moves the industry further away from renewable alternatives. The main contributor is the blast furnace, which uses coal and generally dominates in terms of emissions and energy consumption [7].

Using biomass is one method to combat the emissions. In fact, biomass from the boreal forest has historically been used for steelmaking and contributed in the 18th century to propel Sweden to the top steelmaking nations worldwide. The later use of coal was almost universally adopted during the industrial revolution. Coke (coal treated in a coking process) overtook biomass as a reduction agent in iron making from: 1760 in Britain [8], 1835 in Belgium [8],
1853 in France [8] and at the beginning of the 20th century in Sweden [9]. The superior properties of Coke as bed material, enabled the large and efficient types of blast furnaces used today. The Swedish blast furnaces are listed in Table 1, which are many times larger than the older type. The general understanding is that large blast furnaces cannot function properly with raw or pretreated biomass as bed material. The main constraint is the low compression-strength of biomass at high temperatures, which impairs the passage of gases through the shaft.

Over the years, injection of pulverized coal (PC) has been introduced worldwide in the majority of all blast furnaces [2]-foremost as a cost saving measure. A previous study by some of the authors; Orre et al. [12], investigates the economic impact of introducing a range of injectants, where injections clearly lower the production cost versus an all-coke operating mode. Though, this practice might now pave the way of using significant portions of biofuel. Of the different streams of fossil fuel to the blast furnace, replacing the injection is understood as the easiest way to introduce biomass [2-6]. Thus, in Sweden, the carbon footprint of blast furnaces is possible to reduce significantly and since Sweden has abundant forest resources, favorable conditions exist for companies to pioneer this method.

With recent developments, the blast furnaces in Sweden can now operate with a comparably low total reductant rate, mainly due to large furnace volume and a large portion of high-quality pellets. The low coke rate of $320 \mathrm{~kg} / \mathrm{tHM}$ (for BF M3 in Table 1) is usually not achieved unless a very high PC rate is used (200$230 \mathrm{~kg} / \mathrm{tHM}$ according to Babich et al. [13]). As seen in Table 1, the PC rate for BF M3 is $135 \mathrm{~kg} / \mathrm{tHM}$, which is at the lower end of the European average (130-150 kg/tHM according to Lacroix et al. [14]). Thus, the $\mathrm{CO}_{2}$ emissions are by comparison already low and the possibility of adding varying amounts of biofuels and changing the ratio of coke and coal, gives significant flexibility to balance economics and emissions. Norgate and Langberg [3] investigate the optimal balance, which is directly affected by emission caps and carbon tax. As the caps decreases and taxes increase, flexibility is key to competitive steelmaking. Note that the 2008 numbers for coal and coke rate, which are slightly different, is used in the simulation (155 and $305 \mathrm{~kg} / \mathrm{tHM}$ respectively), total reductant rate is nearly unchanged however. 
Table 1

Blast furnaces in Sweden (2014) [10], with estimated numbers for coal and coke consumption (2008) [11].

\begin{tabular}{|c|c|c|c|c|c|c|c|}
\hline \multirow[t]{2}{*}{$\mathrm{BF}$} & \multirow[t]{2}{*}{ Location } & \multirow[t]{2}{*}{ Coal/coke rate, kg/tHM (2014) } & \multirow[t]{2}{*}{ Working volume, $\mathrm{m}^{3}$} & \multirow[t]{2}{*}{ Capacity, MtHM/year } & \multirow[t]{2}{*}{ Production, MtHM (2008) } & \multicolumn{2}{|c|}{$\begin{array}{l}\text { Consumption, } \\
\text { Mton (2008) }\end{array}$} \\
\hline & & & & & & Coal & Coke \\
\hline M3 & Luleå & $135 / 320$ & 2540 & 2.55 & 2.24 & 0.31 & 0.73 \\
\hline M2 & Oxelösund & $110 / 370$ & 1100 & 0.80 & $1.33^{\mathrm{a}}$ & $0.15^{\mathrm{a}}$ & $0.50^{\mathrm{a}}$ \\
\hline M4 & Oxelösund & $95 / 365$ & 1339 & 1.10 & & & \\
\hline
\end{tabular}

a $2+$ M4.

Other routes of introducing biomass to the blast furnace have been identified, research on mixing coal and biomass in the coking plant have been done by MacPhee et al. [15]. Biomass may also be used to replace coke partially, as bed material, though permeability quickly becomes a problem as the ratio is increased. Hanrot et al. [16] estimates that $20 \mathrm{~kg} / \mathrm{tHM}$ coke can be replaced by charcoal, as this amount is gasified before reaching the thermal reserve zone where permeability is more critical. This is actually positive as the TRZ temperature decreases-by charcoal having higher gasification reactivity [17]-resulting in lower coke consumption. Additionally, the sinter pellets production may be considered a step in steelmaking, Butkovská et al. [18] and Mašlejová [19] investigates biomass use in production of sinter. Norgate and co-workers $[3,4]$ as well as Suopajärvi and co-workers $[5,6]$ consider all these options, where in each case at least partial substitution seems possible. However, of the direct input streams to the blast furnace, the PC is the only one easy to replace by $0-100 \mathrm{wt} \%$ pretreated biomass [16], while at the same time avoiding excessive investments and not jeopardizing the fundamental mechanisms of the blast furnace.

Availability of biomass is naturally another concern. Full substitution, in the Swedish steel industry, requires an amount on the level of national significance. For further reference Johansson [20] evaluates the feasibility of fuel substitution (also in downstream production steps) on a broader level, including organizational, behavioral and regulatory considerations.

In this work the future competing uses of biomass is considered and compared to the predicted availability, which is an important consideration. For instance, production of transportation fuels is a competing high added-value use of biomass; by 2030, the Swedish fleet of vehicles should be fossil-independent, which is a target set by the Swedish government. The existing forestry and agricultural industry cannot meet the demand from existing biomass users, in addition to new demand from transportation and industry. However, unconventional sources (such as stubs, needles, branches and tops) could be used in the future with developments in harvesting methods. Also, as demand for biomass increases, unprofitable regions might be further developed and market as a whole might grow-which is the reason most studies forecast an increase in biomass availability in the coming decades.

If a biofuel would be used in a blast furnace, the infrastructure and pretreatment process must be constructed. The uncertainty and hence the lack of predictions, makes it difficult to evaluate the biomass potential beyond 2030. Still, this time frame is not very far-reaching since the introduction of biomass in the blast furnaces will take time. This is one aspect further investigated in this paper. Finally, the $\mathrm{CO}_{2}$ reductions that may be achieved based on the maximum injection rate of each biofuel is estimated, with considerations for needed biomass. Modeling the injection of biofuels is naturally the first step, before pilot scale experiments and industrial trials.

Other modeling and experimental efforts of investigating Pulverized Coal Injections have been done to see the behavior on a particle level, with aid of, for example Computational Fluid Dynamics (CFD) [21,22] or drop-tube furnaces [23,24]. These types of investigations are useful to study a specific effect in a small zone of the furnace. However, constructing a detailed model of the whole blast furnace is very challenging, considering the numerous physical and chemical phenomena. Another type of model is suggested in works such as Suopajärvi and Fabritius [25], Grip et al. [26], or Sakamoto et al. [7] with the purpose to simulate an integrated steel plant. It is important to evaluate the effects of biofuels on the whole plant, though the most critical considerations for steel company is to ensure that the blast furnace can continue running uninterrupted and maintaining the same performance.

The type of model used in this paper, is appropriate for studying the steady state of a whole blast furnace on a simplified level. The different zones are then, connected by mass and heat exchange and specific metallurgical considerations govern each zone, for example the reactions of hot metal, slag, iron ore pellets, coke, injectants and additives.

\section{Methodology}

The maximum replacement rate for each pretreatment method is first estimated, with subsequent changes in operating conditions, and then translated to a required amount of biomass and a possible net reduction in $\mathrm{CO}_{2}$ emissions. The issues left out in this work are economic aspects and the sustainability of harvesting such large amounts of biomass. This methodology section describes how each step is carried out. Table 2 shows the assumed properties of the $\mathrm{PCI}$ and the biomass products. The considered ones are charcoal, torrefied biomass and pellets (raw but dry and densified biomass)-all from woody biomass, mainly pine and spruce. Note that the moisture content is estimated after storage in a dry environment, which would be realistic in a real plant. But, as with most of these parameters, it would be possible to control them by altering the process conditions and adding more steps; such as reducing ash content by acid washing. The biomass considered in this paper would likely not need any such treatment as the contaminants are low in concentration. However, if a high ash content feedstock would be considered, a screening or leaching step could be introduced.

Table 2

Ultimate analysis of PCI and investigated biomass products [11].

\begin{tabular}{llrlll}
\hline Parameter & Unit & PCI & \multicolumn{3}{c}{ Biomass products [11] } \\
\cline { 3 - 6 } & & & Charcoal & Torrefied material & Wood pellets \\
\hline C & ${\text { wt } \%^{\mathrm{a}}}^{\mathrm{n}}$ & 85.0 & 84.7 & 58.0 & 50.5 \\
$\mathrm{H}$ & wt\% $^{\mathrm{a}}$ & 3.9 & 3.35 & 5.30 & 6.2 \\
$\mathrm{~N}$ & wt $^{\mathrm{a}}$ & 2.1 & 0.13 & 0.48 & 0.1 \\
$\mathrm{O}$ & wt $^{\mathrm{a}}$ & 2.1 & 10.6 & 34.0 & 42.6 \\
$\mathrm{~S}$ & wt\% $^{\mathrm{a}}$ & 0.4 & 0.02 & 0.03 & 0.01 \\
Ash & wt\% $^{\mathrm{a}}$ & 7.8 & 1.9 & 3.2 & 0.5 \\
Moisture & wt\% & 1.0 & 4.5 & 7.7 & 9.4 \\
LHV & $\mathrm{MJ} / \mathrm{kg}$ & 33.5 & 31.6 & 21.6 & 19.2 \\
\hline
\end{tabular}

a Dry basis. 


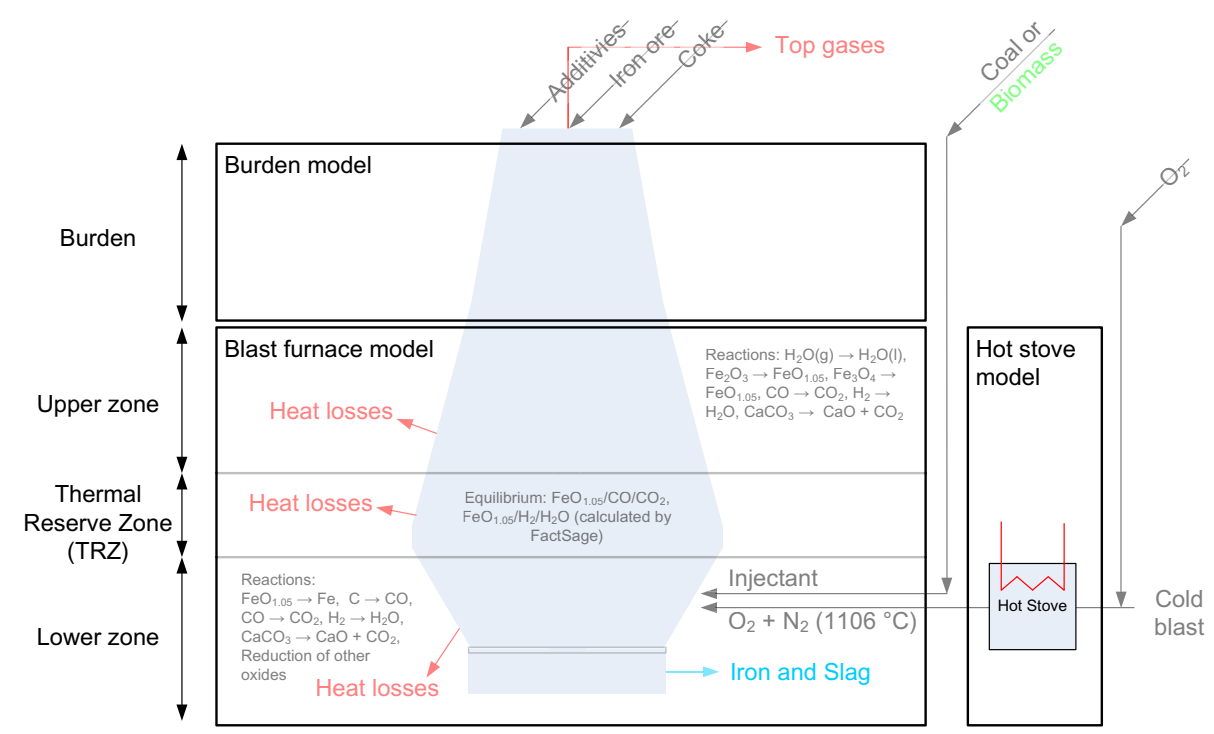

Fig. 1. Blast furnace model used in this paper, showing the different sub-models, zone-specific reactions as well as inlet and outlet streams.

\subsection{Simulation and maximum replacement potential}

A schematic diagram of the model is shown in Fig. 1. This type of model has not previously been used to study the injection of biofuels, which will affect not only the carbon footprint, but also slag generation rate, limestone consumption, chemistry and a number of other factors.

With the outset from pretreatment, the simulation is carried out on a case-by-case basis. A 1-D static, heat and mass balance model (MASMOD) is used, introduced previously by Hooey et al. [27]. Fig. 1 shows the layout of the model, together with the blast furnace and the various input and output streams. The overall scheme links together three sub-models, the blast furnace model, the hot stove model and the burden model. An overall solution is obtained iteratively. The model has previously undergone some platform changes, as of now it is used in a Microsoft Excel environment.

The burden model, balances the required basicity and reduction degree in the blast furnace model, by charging enough materials, including coke, pellets, sinter and additives (limestone and quartz). The blast furnace model (including the lower, upper and thermal reserve zone) calculates a number of reactions given in Fig. 1. The blast furnace model is linked to the hot stove model through the hot blast required. The hot stove is a heat exchanger that preheats the air, i.e. the hot blast to the blast furnace. The energy balance equation in the hot stove model calculates the fuel required to ensure a sufficient heat supply. Commonly, the air combustion technique is applied in the hot stove with Blast Furnace Gas (BFG), which is often mixed with Coke Oven Gas (COG) in order to get a sufficient heating value. For the blast furnace, the amount of injectants required (for both coal and biofuel) is calculated to achieve a constant Raceway Adiabatic Flame Temperature (RAFT). In principle two main parameters limit the application, a maximum oxygen enrichment of the hot blast and a minimum allowed top gas temperature. As the nature of the volatile matter in biomass is different from coal, the extra energy that may be required is considered by introducing a so called "cracking energy" in the calculation of each injectant. More complex and numerous intermolecular bonds are present and the total amount of volatiles is higher; consequently more energy appears to be needed to achieve the combustion (analogous to how high volatile matter coal behaves when injected).
The reference blast furnace used in the simulation is BF M3 in Table 1, designated Masugn 3 by the owner SSAB. The maximum replacement potential is based on (1) the top gas temperature and (2) the oxygen content of the biofuel, which is offset by an oxygen enrichment of the blast-to keep the Raceway Adiabatic Flame Temperature (RAFT) constant. The oxygen enrichment is restricted to a maximum of $25.4 \%$ for practical reasons and the top gas temperature must be above $100{ }^{\circ} \mathrm{C}$ to avoid condensation; these two factors are the main limiting factors for biofuel use. The conditions in Table 3 are furthermore used as a Basecase with $100 \%$ coal. The coke rate is kept constant to ensure a stable operation; other parameters that either varies or is held constant, is given in Table 3 . Note that the coal and coke rate are slightly different in Table 3 (2008), compared to Table 1 (2014), the total reductant rate is nearly unchanged however. The 2008 numbers for coal and coke rate is used, as this represents an uneventful year with high productivity; the reference period is April 28-June 4 with a production rate of $275.7 \mathrm{tHM} / \mathrm{h}$.

The simulation is carried out by increasing gradually the feed rate of biofuels and observing changes in operating conditions. A maximum replacement potential is determined when either of above given conditions are met. At the same time, other factors developed during the simulation, which are reported in the results

Table 3

Key parameters of blast furnace 3 operation for the reference period.

\begin{tabular}{|c|c|c|c|}
\hline Parameter & Unit & $\begin{array}{l}\text { Base case } \\
(100 \% \text { Coal) }\end{array}$ & $\begin{array}{l}\text { Cases of biomass use } \\
(0-100 \%)\end{array}$ \\
\hline \multicolumn{4}{|l|}{ Feed rate } \\
\hline Coke & $\mathrm{kg} / \mathrm{tHM}$ & 305 & Kept constant \\
\hline $\mathrm{PCI}$ & $\mathrm{kg} / \mathrm{tHM}$ & 155 & Varies \\
\hline Biofuel & $\mathrm{kg} / \mathrm{tHM}$ & 0 & Controlling variable \\
\hline Limestone & $\mathrm{kg} / \mathrm{tHM}$ & 41 & Varies \\
\hline \multicolumn{4}{|c|}{ Controlled parameters } \\
\hline $\mathrm{O}_{2}$ in the blast & $\%$ & 23.9 & $<25.4$ \\
\hline RAFT & ${ }^{\circ} \mathrm{C}$ & 2151 & Kept constant \\
\hline Blast temp. & ${ }^{\circ} \mathrm{C}$ & 1106 & Kept constant \\
\hline Top gas temp. & ${ }^{\circ} \mathrm{C}$ & 133 & $>100$ \\
\hline \multicolumn{4}{|c|}{ Operating conditions } \\
\hline Eta $\mathrm{CO}$ & $\%$ & 55.5 & Varies \\
\hline Shaft efficiency & $\%$ & 98.5 & Kept constant \\
\hline Slag formation & $\mathrm{kg} / \mathrm{tHM}$ & 149.6 & Varies \\
\hline
\end{tabular}


section. Any possible energy saving in the blast furnace is estimated according to the inputs and outputs of the system given in Fig. 2. The inputs and outputs given in Fig. 2 are the ones that will change in comparison with base case of $100 \%$ coal.

\subsection{Required vs available biomass in Sweden}

The required amount of raw biomass for each pretreatment, requires the conversion efficiency on both energy and weight basis, which is reported in Table 4. The conversion technologies considered in this paper are (1) pelletization (produces a dry and densified product which is clearly defined and widely available), (2) torrefaction and (3) pyrolysis, which all can use various kinds of forest residue. The other conversion technologies in Table 4 yield, for Hydrothermal Carbonization (HTC) and Steam Explosion (SE), a product similar to torrefied biomass. HTC is normally used for biomass with already high moisture content, such as sewage sludge. SE is similar to torrefaction, however, by use of highpressure steam, the biomass structure is altered to be more susceptible to pelletization. LignoBoost produces, from the lignin fraction generated in the pulping process, a pelletized product similar to coal. Note that shaping of biomass into pellets has no effect within the context of the model. Instead pelletization is specified as the product meets clearly defined standards (low moisture content, ash content, etc.) and is widely available.

The raw biomass availability is an actively investigated issue in Sweden, as the industrial interest for biomass is considerable. To evaluate the biomass availability for use in blast furnaces, a long term view is appropriate. Table 5 shows a summary of supplypotential studies in Sweden that also predicts the development until 2050. The minimum prediction and maximum prediction are given for each decennium with the number of studies indicated in brackets. In the case, most notably 2050, where a value is given by just one prediction, the specific study is indicated. As seen, most studies are limited to 2030 due to the uncertainty; this is reflected by a drop of the average value of supply potential. It seems the longer predictions are conservative in terms of estimates and the expansion of potential predicted by many, levels-off after 2030.
Svebio [28] estimated the potential for all types of biomass, including peat and waste. The long term potential of biomass can be as high as 394 TWh per year, of which agricultural biomass can play a significant role.

The blast furnace will primarily use forest biomass, though we base our calculations on total biomass availability. This is relevant since elasticity should be expected-meaning that companies with low-value products will switch to other fuels (or raw materials) with lower value. For example, boilers are expected to use more waste in the future, leaving more forest biomass for the blast furnaces. Transportation fuels can be produced-via gasification or catalytic fast pyrolysis for example-from other biomass sources as well and do not require forest biomass specifically.

In Table 6 a base scenario from Energimyndigheten (Andersson et al. [31]) is given, which assumes that the iron and steel industry continue using fossil fuels-thus we avoid double counting-and the rest of the industry remains the same and only develops according to existing regulations.

Table 6 also includes two scenarios from Hansson and Grahn [32] concerning the increased use of biomass for transportation, which is an ambition set by the Swedish government. The competing uses of biomass are an important factor for the economic viability. Scenario 1 assumes a completion of all initiated projects. Scenario 2 assumes an expansion beyond the current plans with more actors entering the market.

\subsection{Reduction in $\mathrm{CO}_{2}$ emissions}

The specific tonnage reduced, is based on the physical amount of $\mathrm{CO}_{2}$, otherwise emitted by the coal. According to the European Commission, substitution of coal by biomass in the industry should be regarded as a $100 \%$ reduction in $\mathrm{CO}_{2}$ emissions. This means that biomass is completely carbon neutral. Although disputed, this is the leading assumption in this paper. For further reference, Suopajärvi et al. [6] and Burchart-Korol [33], investigates it in detail by LCA and stresses that all aspects (transports, land-use, etc.) should be considered given the option to use biomass or continue using fossil fuels. However, the carbon footprint indicator in

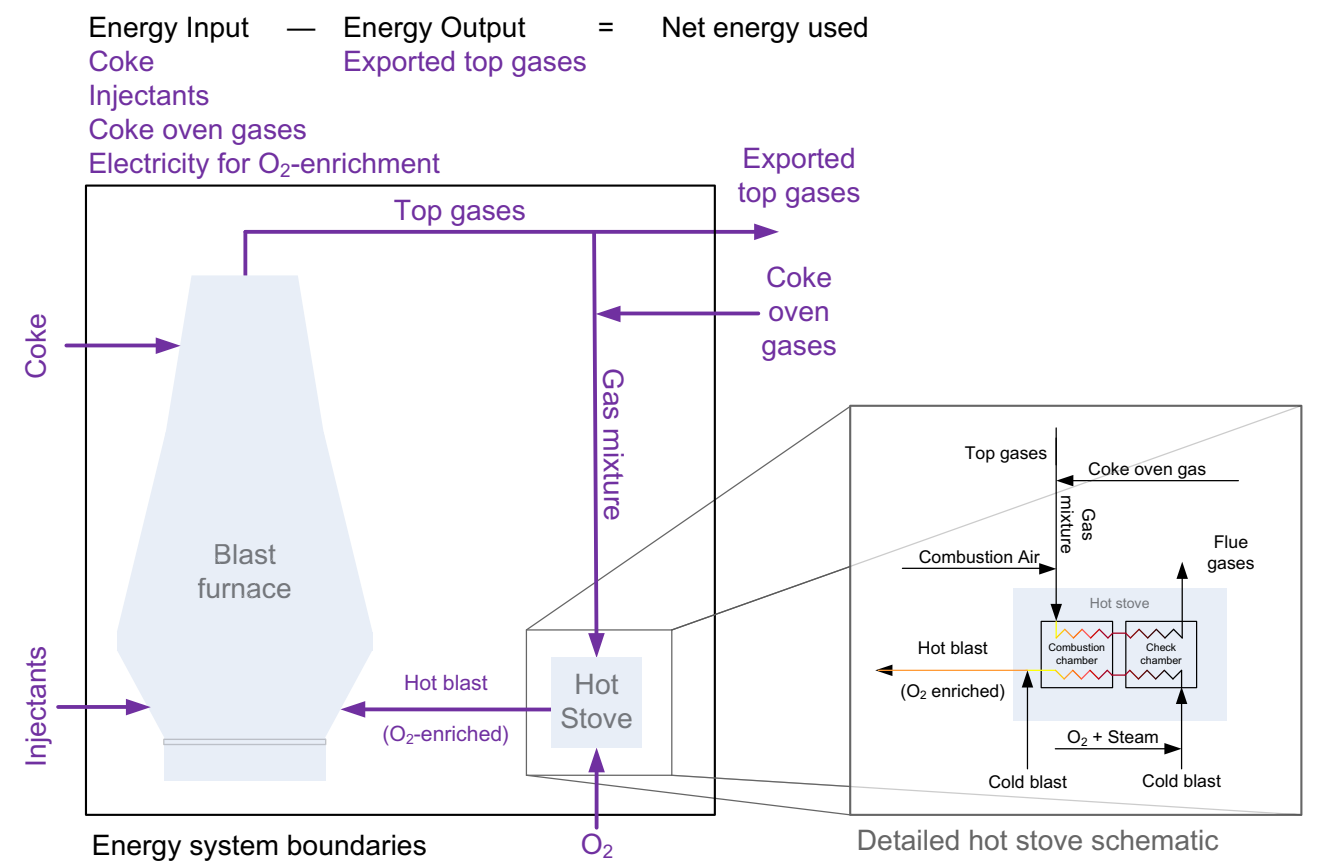

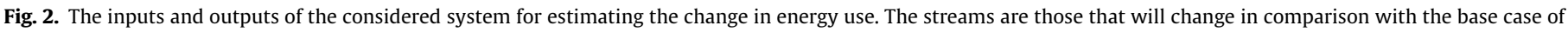
$100 \%$ coal use. A detailed hot stove schematic is also shown to provide additional information on how energy saving is calculated in the results section. 
Table 4

Details of available solid conversion technologies shown in for biomass in Sweden [11].

\begin{tabular}{|c|c|c|c|c|c|c|}
\hline \multirow[t]{2}{*}{ Parameter, unit } & \multicolumn{6}{|c|}{ Solid conversion process } \\
\hline & Pelletization & Pyrolysis & Torrefaction & Steam Explosion & HTC & LignoBoost \\
\hline Temp, ${ }^{\circ} \mathrm{C}$ & 70 & $400-500$ & $200-300$ & $160-260$ & $180-220$ & 70 \\
\hline Pressure, MPa & High & - & - & $0.7-5$ & $2.3-2.5$ & High \\
\hline Product & Wood pellets & Charcoal & Torrefied material & SE biomass & HTC biomass & Pellets \\
\hline Yield, wt\% & $\sim 100$ & 35 & 70 & 70 & 70 & $\sim 100$ \\
\hline Yield, energy\% & $\sim 100$ & 56 & 90 & 79 & 80 & $\sim 100$ \\
\hline Source & Several & Skogens kol & Torkapparater & SEKAB & KTH & Several \\
\hline Production & $2.3 \mathrm{Mton} / \mathrm{y}$ & 6000 ton/y & 1 ton $/ \mathrm{h}$ & - & - & 2.3 Mton/y \\
\hline Status & Industrial use & Small scale & Pilot & Pilot & Lab & Commercial \\
\hline Price, $€ / M W h$ & 33 & 55 & $39.5-67.7$ & - & 29.2 & 33 \\
\hline
\end{tabular}

Table 5

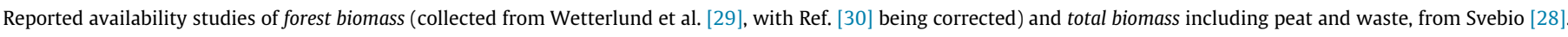

\begin{tabular}{|c|c|c|c|c|c|c|c|}
\hline \multirow[t]{2}{*}{ Ref. } & \multirow[t]{2}{*}{ Biomass } & \multicolumn{6}{|c|}{ Interval (number of studies), TWh/year } \\
\hline & & 2000 & 2010 & 2020 & 2030 & 2040 & 2050 \\
\hline \multirow[t]{4}{*}{ [29] } & Primary forest & $16-113.5(23)$ & $25.8-111.0(14)$ & $16.0-126.0(16)$ & $16.0-71.2(7)$ & (0) & $18-52(3)$ \\
\hline & Secondary residue & $12-44(13)$ & $20-59.6(6)$ & $16.8-63.7(9)$ & $40.0-68.1(2)$ & (0) & $60(1)[30]$ \\
\hline & Stump & $0.3-8.0(5)$ & $10.0-57.5(4)$ & $10.0(1)$ & (0) & (0) & (0) \\
\hline & Total forest biomass & $80-159.6(3)$ & $111.0-173.8(3)$ & 107.0-181.7 (7) & $143-195.2(2)$ & (0) & 157 (1) [30] \\
\hline [28] & Total biomass & $(0)$ & $(0)$ & $248(1)$ & (0) & (0) & $394 *(1)$ \\
\hline
\end{tabular}

${ }^{*}$ Long term.

Table 6

Estimated use of biomass, excluding Peat and Waste.

\begin{tabular}{|c|c|c|c|c|}
\hline \multirow[t]{2}{*}{ Ref. } & \multirow[t]{2}{*}{ Sector (Scenario) } & \multicolumn{3}{|c|}{$\begin{array}{l}\text { Estimated use based on } \\
\text { regulation, TWh/year }\end{array}$} \\
\hline & & 2007 & 2020 & 2030 \\
\hline \multirow[t]{6}{*}{ [31] } & Industry & 55.1 & 64.3 & 69 \\
\hline & Transportation & 3.5 & 6.2 & 6.4 \\
\hline & Residential and service & 13.9 & 13.9 & 16.4 \\
\hline & Electricity & 12 & 19.5 & 20.5 \\
\hline & Heating & 36.5 & 44 & 43.7 \\
\hline & Total & 121 & 150.4 & 155 \\
\hline \multirow[t]{2}{*}{ [32] } & Transportation $^{\mathrm{a}}$ (Scenario 1) & 3.5 & 26 & 30 \\
\hline & Transportation $^{\mathrm{a}}$ (Scenario 2) & 3.5 & 28 & 50 \\
\hline
\end{tabular}

a Assuming a conversion efficiency of $50 \%$ on energy basis.

Burchart-Korol [33] shows that for wood chips, this factor is unmistakably in favor of using biomass. Other factors like land occupation are in favor of using coal and regarding toxicity to humans, both choices are about the same. Another factor is of course the sustainability of harvesting a high level of residue with a fast rotation rate, which is investigated in other works-see for example Egnell and Börjeson [34].

\section{Results}

\subsection{Maximum replacement potential}

The low energy density of biofuels is caused by a higher oxygen content, which in turn forces an additional oxygen enrichment of the blast. In this way, the RAFT is kept constant in order to ensure stable operating conditions. Likewise, a number of other parameters are kept constant, which is shown in Table 3 (note that this list of parameters is not exhaustive).

By increasing the feed rate in the simulations, several changes in the operating conditions can be observed. A replacement limit is reached for wood pellets and torrefied material, since the $\mathrm{O}_{2}$ enrichment cannot exceed 25.4\%; see Fig. 3(a). Charcoal can replace coal fully, although an $\mathrm{O}_{2}$ content of $24.6 \%$ is needed, compared to 23.9 in case of $100 \%$ coal. On the other hand, low sulfur and gangue content as well as a high volatile content, results in a potentially lower limestone consumption; see Fig. 3(c). This in turn reduces the slag generation rate, which is an important impact of biofuel use. As seen in that graph, it is most pronounced in the case of Charcoal.

At the maximum level of replacement, the total amount of required energy and mass input increases, for all biofuels-see Fig. 3(b). This is mainly, but not exclusively due to the lower energy density. In principal, a larger amount of combustion products should reach a fixed temperature, hence more energy is needed. But as mentioned in the methodology section a "cracking energy" is also needed, requiring additional input energy.

Despite the high energy-need for injections. Substantial energy savings are likely possible, considering the system of an integrated plant (Fig. 2). For each biofuel, a calculated energy saving is shown in Fig. 3(d), which is one of the main findings in this paper. The reason is explained by the following paragraphs.

With the oxygen enrichment into the hot blast, the required hot blast volume becomes lower, consequently the energy consumption in the hot stove will decrease, especially for COG. In addition, more BFG will be generated, which will lead to a potential energy saving in the integrated plant where BFG is used as a fuel. A corresponding decrease in the top gas temperature is shown in Fig. 3(c). The sensible heat in the top gas cannot be recovered as the temperature is too low. But as the latent heat increases when biofuels are used, more can be exported outside the boundaries of Fig. 2. Thus an energy saving-by top gas replacing other fuels in the steel plant-is predicted, see Fig. 3(d). Due to the above reasons, for a high hot metal production rate, the estimated energy saving can be as large as $168.9 \mathrm{GWh}$ per year when using wood pellets. The main reason is that wood pellets have higher oxygen content (see Table 2).

Fig. 4 shows how the energy saving is added up which corresponds to the inputs and outputs of the energy system defined in Fig. 2. More blast furnace gas is generated and less coke oven gas is needed, considering the boundaries of Fig. 2. At the same time extra injectants and electricity for oxygen enrichment is needed, 
(a) Limits of biofuel replacement and resulting total injectant rate

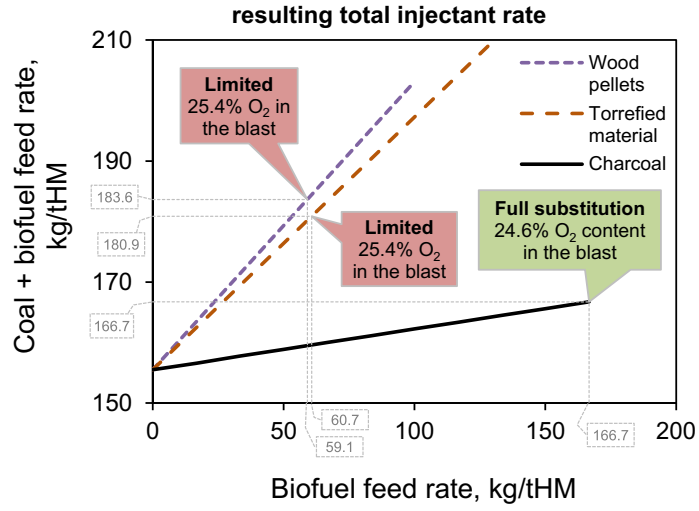

(c) Resulting limestone use, slag output rate and top gas temperature

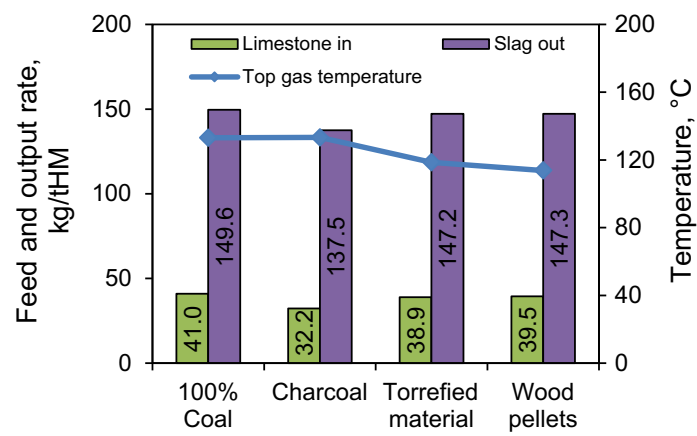

(b) Proportions at maximum replacement and change in total

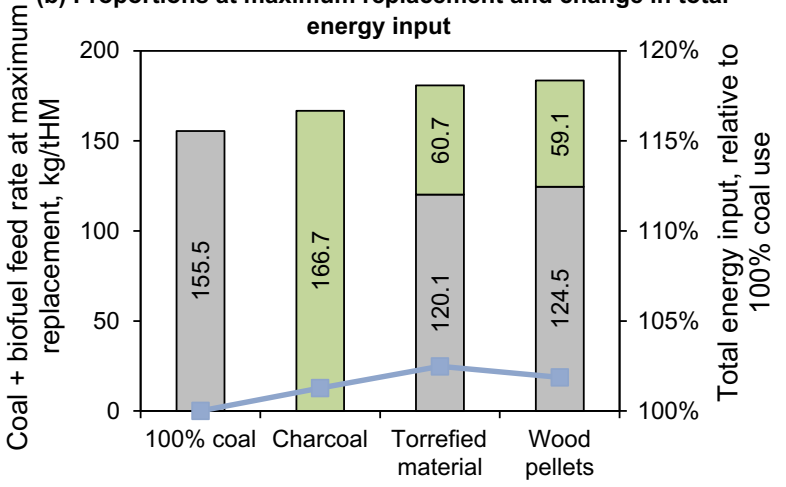

(d) Resulting energy saving potential, considering input and output streams in Figure 2, compared to $100 \%$ coal use

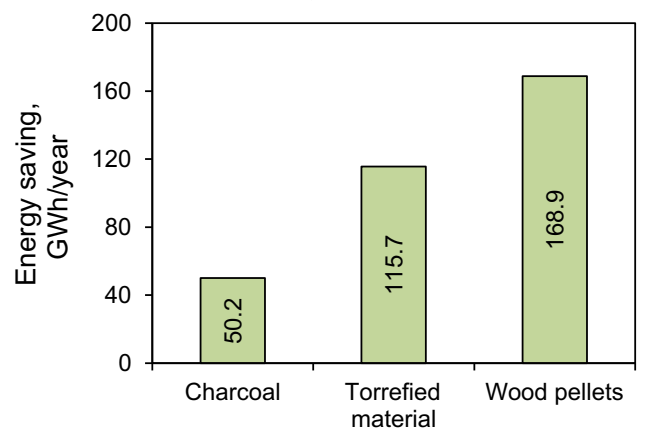

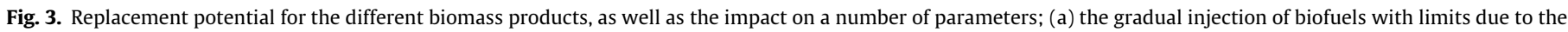

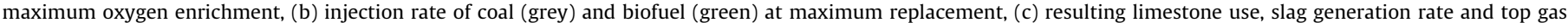
temperature, (d) potential energy saving due to top gas generation rate according to the input and output streams within the boundaries shown in Fig. 2.

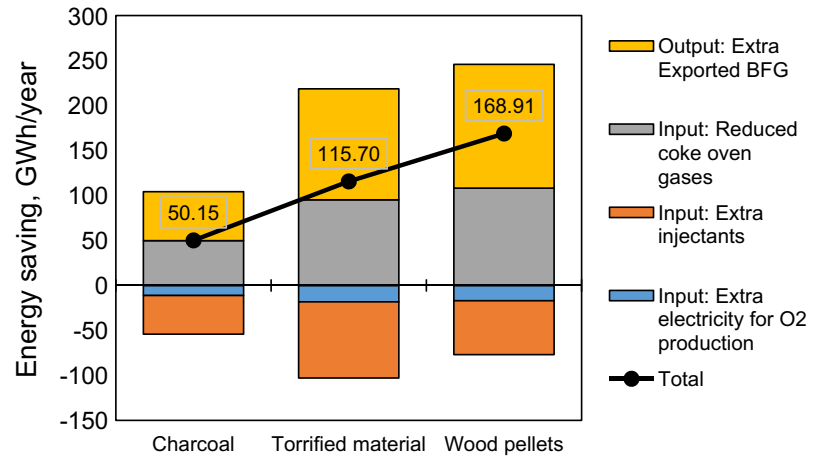

Fig. 4. Energy saving, added up from the change in needed coke oven gas, injectants and electricity for $\mathrm{O}_{2}$ production versus produced blast furnace gas.

see Fig. 4. For wood pellets, a number of factors favorably combine, resulting in the highest energy saving.

\subsection{Required vs available biomass in Sweden}

The blast furnace will primarily use forest biomass, though we base our calculations on total biomass availability. This is relevant since elasticity should be expected-meaning that companies with low-value products will switch to other fuels or raw materials with lower value. For example, boilers are expected to use more waste in the future, leaving more forest biomass for the blast furnaces.

The uncertainty and hence the lack of predictions, makes it difficult-beyond 2030-to evaluate the available biomass for injection into blast furnaces. Still, this timeframe is not very far-reaching since the introduction of biomass will take time.
Though, most studies forecast a growing total availability of biomass, as increased use is expected to drive the development of remote locations and harvesting methods. On the other hand, if the use reaches too high levels, the economic viability will suffer. Considering the significant competition expected in the south of Sweden, as well as the required development of costly infrastructure, BF M3 is primarily suitable for a switch to biomass.

Fig. 5 shows the location of the blast furnaces and the used amount of coal; other primary biomass users are also shown as to give the regional circumstances. In the north of Sweden (where BF M3 in Table 1 is located), a larger unused potential is expected, and it is hence the logical place to start-out with biomass injection. As indicated in Fig. 5, an unused potential of forest biomass exists today, about $0.7 \mathrm{TWh} / \mathrm{y}$ for both Västerbotten $(377 \mathrm{GWh} / \mathrm{y})$ and Norrbotten (359 GWh/y).

On the right hand side of Fig. 5, the long-term predictions of potential secondary forest residue, total forest biomass and total biomass; are shown (reported in Table 5). In the midterm, until 2030, potentially available biomass is expected to grow; error bars indicate the maximum and minimum prediction if several studies are considered.

The biomass availability of Svebio [28] is shown in Fig. 6 divided into peat ( $\tan$ ), waste (yellow), agricultural residue (orange), black liquor (blue) and wood fuels (light green). Forecasts of the biomass-use, for a number of scenarios, are also shown in Fig. 6 (reported in Table 6). The scenarios (indicated as deep red, red and pink respectively) include a base scenario from Energimyndigheten (Andersson et al. [31], see Table 6) and an increase in biomass use for transportation ( 1 and 2 from Hansson and Grahn [32], see Table 6). The expanded use of biomass for transportation would demand large amounts of biofuel. In the 


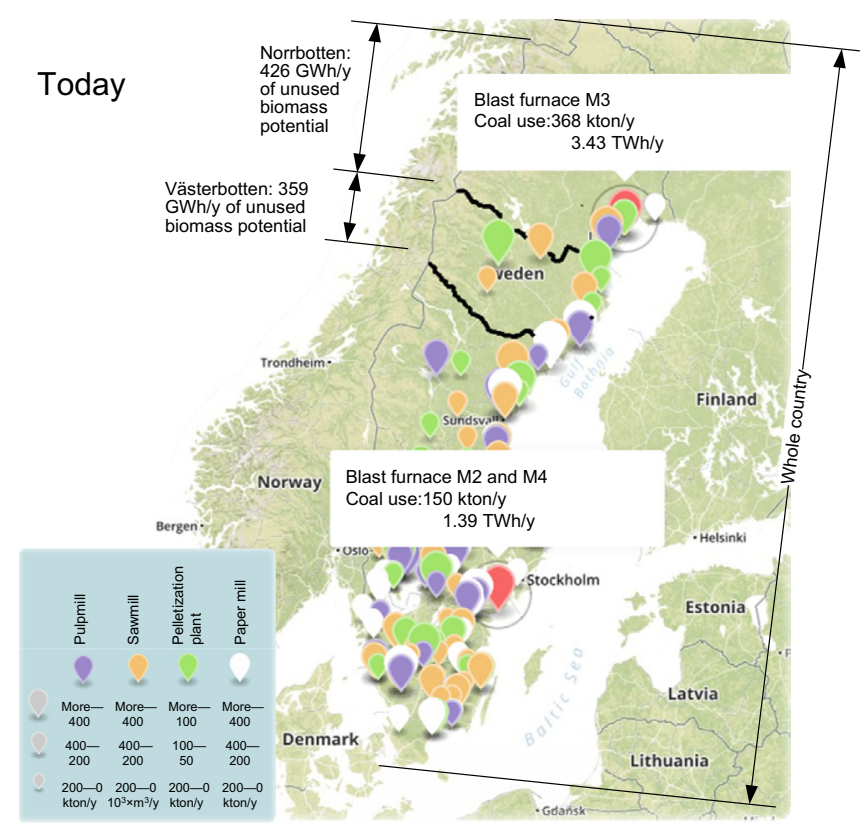

Future availability in whole Sweden

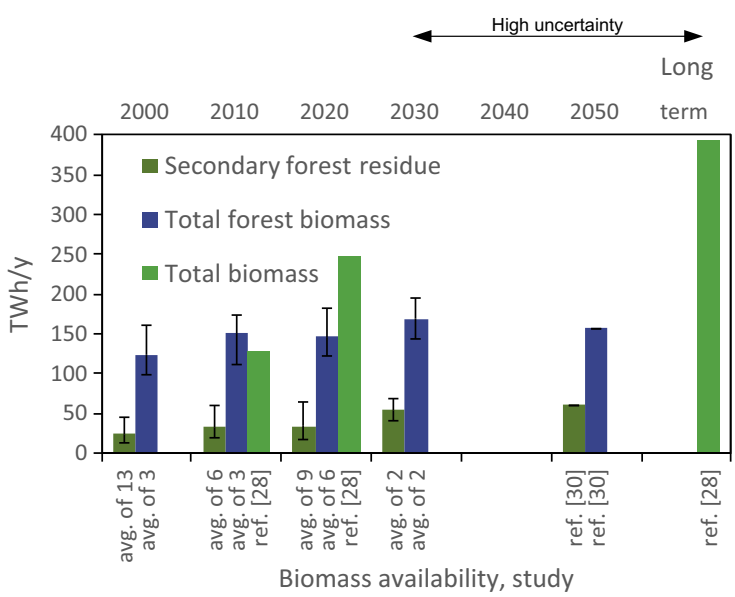

Fig. 5. The location of the blast furnaces, the competing user and the available as well as development in potentially available biomass. Error bars are for given the maximum and minimum prediction, in the case where several studies overlay.

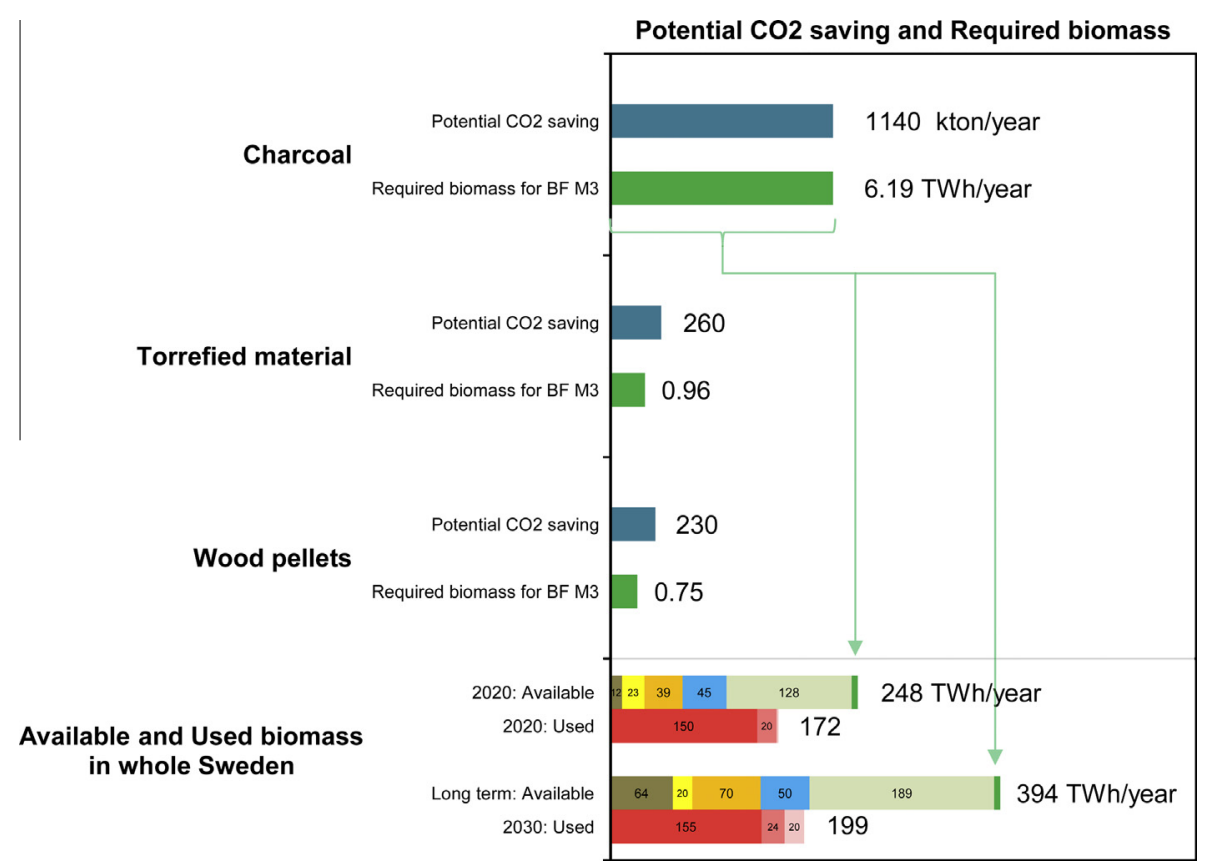

Fig. 6. Potential $\mathrm{CO}_{2}$ saving and the required biomass for maximum replacement of $\mathrm{PCI}$ for each biomass product in blast furnace $\mathrm{M} 3$. The required biomass are then compared to the available biomass by arrows. Availability [28] is divided into peat (tan), waste (yellow), agricultural residue (orange), black liquor (blue) and wood fuels (light green). Predicted use from Table 6 [31] (deep red) is shown, in addition to the scenarios from Table 6 [32] (red and pink) of extensive biomass-use of transportation. (For interpretation of the references to colour in this figure legend, the reader is referred to the web version of this article.)

scenario with the highest use for transportation, by 2030 the required biomass will exceed the available forest biomass (shown in Fig. 5 and as light green in Fig. 6; note that the highest prediction is not exceeded-only the average). While imports might cover the difference, the competition for forest biomass in particular will be severe by 2030-if transportation will become a major biomassconsumer.

Also shown in Fig. 6, is the required pulverized coal for BF M3 (considering $8760 \mathrm{~h} / \mathrm{y}$ with $98 \%$ operating availability and a production rate of $275.7 \mathrm{tHM} / \mathrm{h}$ ) which amounts to $368 \mathrm{kton} / \mathrm{y}$. Replacement by charcoal requires $7.2 \%$ more weight according to the simulations for BF M3, see Fig. 3 b); as such 394 kton is required, or 3.43 TWh. By using the energy and mass output yield of $56 \%$ and $35 \%$ respectively from Table $4 ; 6.19$ TWh or 1.13 Mton of dry raw biomass will be needed for conversion to charcoal and full replacement of coal. The green area, in Fig. 6, shows this amount in relation to the expected total biomass use and availability, in the future. This is a significant portion of the used biomass 
today, such amounts are not readily available in the market (compare, for example $6.19 \mathrm{TWh} / \mathrm{y}$ for the case of charcoal, with the available $0.7 \mathrm{TWh} / \mathrm{y}$ in the north of Sweden, see Fig. 5). But, as the biomass potential is expected to grow in the long term, enough is likely to be available-especially as Blast Furnace M3 is located in a less densely populated area.

\subsection{Reduction in $\mathrm{CO}_{2}$ emissions}

Finally, for $\mathrm{BF} \mathrm{M} 3$, the possible $\mathrm{CO}_{2}$ reductions are given in Fig. 6. This is at the maximum replacement limit of each biofuel. By using charcoal, the largest reduction is possible, since $100 \%$ replacement is possible. At the same time the highest relative need of raw biomass is required.

For reference the plant in Luleå emitted an estimated 3.7 Mton $\mathrm{CO}_{2}$ in 2008. The same year, Swedish steel industry emitted an estimated 6.6 Mton $\mathrm{CO}_{2}$ [11]. By replacing the injection completely with charcoal, the on-site emissions can be reduced by $28.1 \%$; torrefied material and wood pellets can reduce a maximum of $6.4 \%$ and $5.7 \%$ respectively. The reduction is also substantial on an industry-level; replacing the coal used in this furnace alone, would cut the emissions of the whole industry by $17.3 \%$.

\section{Conclusions}

The result of the simulation indicates a full replacement potential for charcoal, a replacement potential of $22.8 \%$ for torrefied material and $20 \%$ for raw wood pellets. No alkali-related problems are predicted by the model. Instead a number operational benefits were found when using biomass; (1) more Blast Furnace Gas (BFG) will be generated resulting in reduced fuel consumption in an integrated plant, (2) lower need of limestone can be expected, (3) lower slag generation rate as well and (4) less energy is required for heating the hot blast since oxygen enrichment reduces the total volume of gas. An energy saving potential of 50.2, 115.7 and 168.9 GWh/year has been estimated for charcoal, torrefied material and wood pellets respectively. Though, further work is required to understand all impacts. Technical and economic constraints might still arise, linked to for example, logistic issues or quality aspects of the produced iron. During further work, experimental tests and industrial trials, in addition to models should be used.

There is a potential for increased use of biomass, though predictions indicate that strong competition can be expected, especially in the south of Sweden. However, as much as would be needed to replace $\mathrm{PCI}$ in BF M3 should be available in the short term (by $2020,128 \mathrm{TWh} / \mathrm{y})$ and long term (189 TWh/y), considering the developments of remote regions and harvesting methods. Other industries are all interested in using more biomass; the development in each industry will affect the economic feasibility of using biomass in the steel industry. Most notably, biomass for transportation fuels would affect the economic viability of using biomass in the steel industry. As presented in Fig. 6, the total biomass use, according to the base scenario is for the short term $150 \mathrm{TWh} / \mathrm{y}$ (by 2020) and long term $155 \mathrm{TWh} / \mathrm{y}$ (by 2030). Large scale conversion to transportation fuels results in a total biomass use of $172 \mathrm{TWh} / \mathrm{y}$ (2020) and $199 \mathrm{TWh} / \mathrm{y}$ (2030) respectively. Note that this is not limited to forest biomass.

Finally, favorable conditions exist for companies to pioneer this method in Sweden; in this paper considering the availability of biomass, technical limitations of the blast furnace operation and the payoff of greatly reducing emissions. Completely replacing the injected coal by charcoal in this furnace, will reduce the on-site emissions by $28.1 \%$ (torrefied material and wood pellets can reduce a maximum of $6.4 \%$ and $5.7 \%$ respectively) or $17.3 \%$ of the emissions from the whole industry.

\section{Acknowledgements}

The authors thankfully acknowledge the Swedish Energy Agency (Energimyndigheten) for financial support of the research work (project number: 35819-1). For additional financial support, the following companies and institutions are acknowledged; SCA, Sveaskog, Swerea MEFOS and KTH. For support in other ways, the following project partners are also acknowledged; LKAB and SSAB. We are grateful to all above-named organizations for the opportunity to carry out this research.

\section{References}

[1] The Steel Eco-Cycle, Scientific Report 2004-2012, D853. Jernkontoret Research; 2012. <http://www.jernkontoret.se/ladda_hem_och_bestall/publikationer/ stalforskning/rapporter/D_853.pdf>.

[2] Feliciano-Bruzual C. Charcoal injection in blast furnaces (Bio- $\mathrm{PCI}$ ): $\mathrm{CO}_{2}$ reduction potential and economic prospects. J Mater Res Technol 2014;3(3):233-43. http://dx.doi.org/10.1016/j.jmrt.2014.06.001.

[3] Norgate T, Langberg D. Environmental and economic aspects of charcoal use in steelmaking. ISIJ Int 2009;49(4):587-95.

[4] Norgate T, Haque N, Somerville M, Jahanshahi S. Biomass as a source of renewable carbon for iron and steelmaking. ISIJ Int 2012;52(8):1472-81.

[5] Suopajärvi H, Fabritius T. Towards more sustainable ironmaking-an analysis of energy wood availability in Finland and the economics of charcoal production. Sustainability 2013;5(3):1188-207. http://dx.doi.org/10.3390/ su5031188.

[6] Suopajärvi $H$, Pongrácz E, Fabritius T. The potential of using biomass-based reducing agents in the blast furnace: a review of thermochemical conversion technologies and assessments related to sustainability. Renew Sustain Energy Rev 2013;25:511-28. http://dx.doi.org/10.1016/j.rser.2013.05.005.

[7] Sakamoto Y, Tonooka Y, Yanagisawa Y. Estimation of energy consumption for each process in the Japanese steel industry: a process analysis. Energy Convers Manage 1999;40(11):1129-40. http://dx.doi.org/10.1016/s0196-8904(99) 00025-4.

[8] Fremdling R. Foreign trade-transfer-adaptation: the British iron making technology on the continent (Belgium and France). Groningen Growth and Development Centre. University of Groningen; 2002. 200255. <http://ideas. repec.org/p/dgr/rugggd/200255.html>.

[9] Arpi G. The supply with charcoal of the Swedish iron industry from 1830 to 1950. Geogr Ann 1953;35(1):11-27. http://www.jstor.org/stable/520263.

[10] Olsson E. Private communication. SSAB EMEA; 2014.

[11] Wei W, Mellin P, Yang W, Wang C, Hultgren A, Salman H. Utilization of biomass for blast furnace in Sweden - report I: Biomass availability and upgrading technologies. KTH Royal Institute of Technology; 2013. http://urn. kb.se/resolve?urn=urn:nbn:se:kth:diva-138493.

[12] Orre J, Wang C, Larsson J, Olsson E. Potential impacts on the energy system at the integrated steelwork by changing injection coal types to the blast furnace. Chem Eng Trans 2013;35:973-8. http://dx.doi.org/10.3303/cet1335162.

[13] Babich A, Gudenau HW, Senk D, Formoso A, Menendez JL, Kochura V. Experimental modelling and measurements in the raceway when injecting auxiliary substances. In: Proceedings of the international blast furnace lower zone symposium. Wollongong, Australia; 25-27 November 2002. p. 1-14 <http://meveus.iehk.rwth-aachen.de/moodle/file.php/1/homepage/papers/122 Wollongong_2002_Raceway.pdf>.

[14] Lacroix P, Dauwels G, Dufresne P, Godijn R, Perini PG, Stricker KP, et al. High blast furnaces productivity operations with low coke rates in the European Union. Metall Res Technol 2001;3(98):259-68. http://dx.doi.org/10.1051/ metal:2001181.

[15] MacPhee JA, Gransden JF, Giroux L, Price JT. Possible $\mathrm{CO}_{2}$ mitigation via addition of charcoal to coking coal blends. Fuel Process Technol 2009;90(1):16-20. http://dx.doi.org/10.1016/i.fuproc.2008.07.007.

[16] Hanrot F, Sert D, Delinchant J, Pietruck R, Bürgler T, Babich A, et al. $\mathrm{CO}_{2}$ mitigation for steelmaking using charcoal and plastics wastes as reducing agents and secondary raw materials. In: Proceedings of the 1st Spanish national conference on advances in materials recycling and eco-energy. Madrid, Spain; 12-13 November 2009. <http://hdl.handle.net/10261/18433>.

[17] Ng KW, MacPhee JA, Giroux L, Todoschuk T. Reactivity of bio-coke with $\mathrm{CO}_{2}$. Fuel Process Technol 2011;92(4):801-4. http://dx.doi.org/10.1016/i.fuproc. 2010.08.005.

[18] Butkovská M, Fröhlichová M, Findorák R, Legemza J, Ivanišin D. Influence of charcoal on quality of agglomorate. In: Proceedings of acta metallurgica slovaca, vol. 4; 2014. p. 9-16. doi: 10.12776/amsc.v4i0.258.

[19] Mašlejová S. Utilization of biomass in ironmaking. In: Proceedings of the 22nd international conference on metallurgy and materials (Metal 2013); 2013. <http://www.metal2014.com/files/proceedings/12/reports/1744.pdf>. 
ARTICLE IN PRESS

10

C. Wang et al./Energy Conversion and Management $x x x$ (2015) $x x x-x x x$

[20] Johnson MT. Improved energy efficiency and fuel substitution in the iron and steel industry. Linköping University; 2014. http://urn.kb.se/resolve?urn= urn:nbn:se:liu:diva-105849.

[21] Du SW, Chen WH, Lucas J. Performances of pulverized coal injection in blowpipe and tuyere at various operational conditions. Energy Convers Manage 2007;48(7):2069-76. http://dx.doi.org/10.1016/j.enconman.2007. $\underline{01.013}$

[22] Meier C, Jordan C, Feilmayr C, Thaler C, Harasek M. Multi-scale modeling of hydrocarbon injection into the blast furnace raceway. In: Proceedings of the 10th international conference on CFD in oil \& gas, metallurgical and process industries (CFD2014); 2014. <http://www.sintef.no/project/CDF2014/docs/ Official_Proceedings_CFD2014\%20redusert\%20filstr.pdf $>$.

[23] Chen WH, Du SW, Yang TH. Volatile release and particle formation characteristics of injected pulverized coal in blast furnaces. Energy Convers Manage 2007;48(7):2025-33. http://dx.doi.org/10.1016/j.enconman.2007. $\underline{01.001}$

[24] Chen WH, Du SW, Thai CH, Wang ZY. Torrefied biomasses in a drop tube furnace to evaluate their utility in blast furnaces. Bioresour Techno 2012;111:433-8. http://dx.doi.org/10.1016/i.biortech.2012.01.163.

[25] Suopajärvi H, Fabritius T. Effects of biomass use in integrated steel plant gate-to-gate life cycle inventory method. ISIJ Int 2012;52(5):779-87.

[26] Grip CE, Larson M, Harvey S, Nilsson L. Process integration. Tests and application of different tools on an integrated steelmaking site. Appl Therm Eng 2013;53(2):366-72. http://dx.doi.org/10.1016/j.applthermaleng.2012. $\underline{03.040}$.
[27] Hooey P, Bodén A, Wang C, Grip CE, Jonson B. Design and application of a spreadsheet-based model of the blast furnace factory. ISIJ Int 2010;50(7):924-30.

[28] Svebio. Potentialen för bioenergi - tillgång - användning. Svebio; 2008. <http://www.svebio.se/sites/default/files/Potentialen\%20f\%C3\%B6r\% 20bioenergi.pdf>.

[29] Wetterlund E, Pettersson K, Mossberg J, Torén J, Hoffstedt C, won Schenck A, et al. Optimal localisation of next generation biofuel production in Sweden. The Swedish Knowledge Centre for Renewable Fuels (f3); 2013. http://f3centre.se/ sites/default/files/f3_report_2013-8_optimal_localisation_130517_0.pdf.

[30] Kommissionen mot oljeberoende. På väg mot it oljefritt Sverige. Stadsrådsberedningen; 2006. <http://www.regeringen.se/sb/d/108/a/66280>.

[31] Anderson D, Anners C, Nilsson L, Svensson E, Kadic Z, Sahlin M, et al. Långsiktsprognos 2012. Energimyndighet report; $2013 . \quad<$ https:// energimyndigheten.a-w2m.se/Home.mvc?ResourceId=2698>.

[32] Hanson J, Gran M. Utsikt för förnybara drivmedel i Sverige. IVL Svenska Miljöinstitutet; 2013. <http://spbi.se/wp-content/uploads/2013/03/IVL_ B2083_2013_final.pdf>.

[33] Burchart-Korol D. Sustainability and eco-efficiency assessment of biomass use in steelmaking. In: Proceedings of the 22nd international conference on metallurgy and materials (Metal 2013); 2013. <http://www. metal2014.com/files/proceedings/12/reports/1447.pdf>.

[34] Egnell G, Börjeson P. Theoretical versus market available supply of biomass for energy from long-rotation forestry and agriculture - Swedish experiences. IEA bioenergy report; 2012. <http://ieabioenergytask43.org/wp-content/uploads/ 2013/09/IEA_Bioenergy_Task43_TR2012-02.pdf>.

Please cite this article in press as: Wang C et al. Biomass as blast furnace injectant - Considering availability, pretreatment and deployment in the Swedish

steel industry. Energy Convers Manage (2015), http://dx.doi.org/10.1016/j.enconman.2015.04.013 